
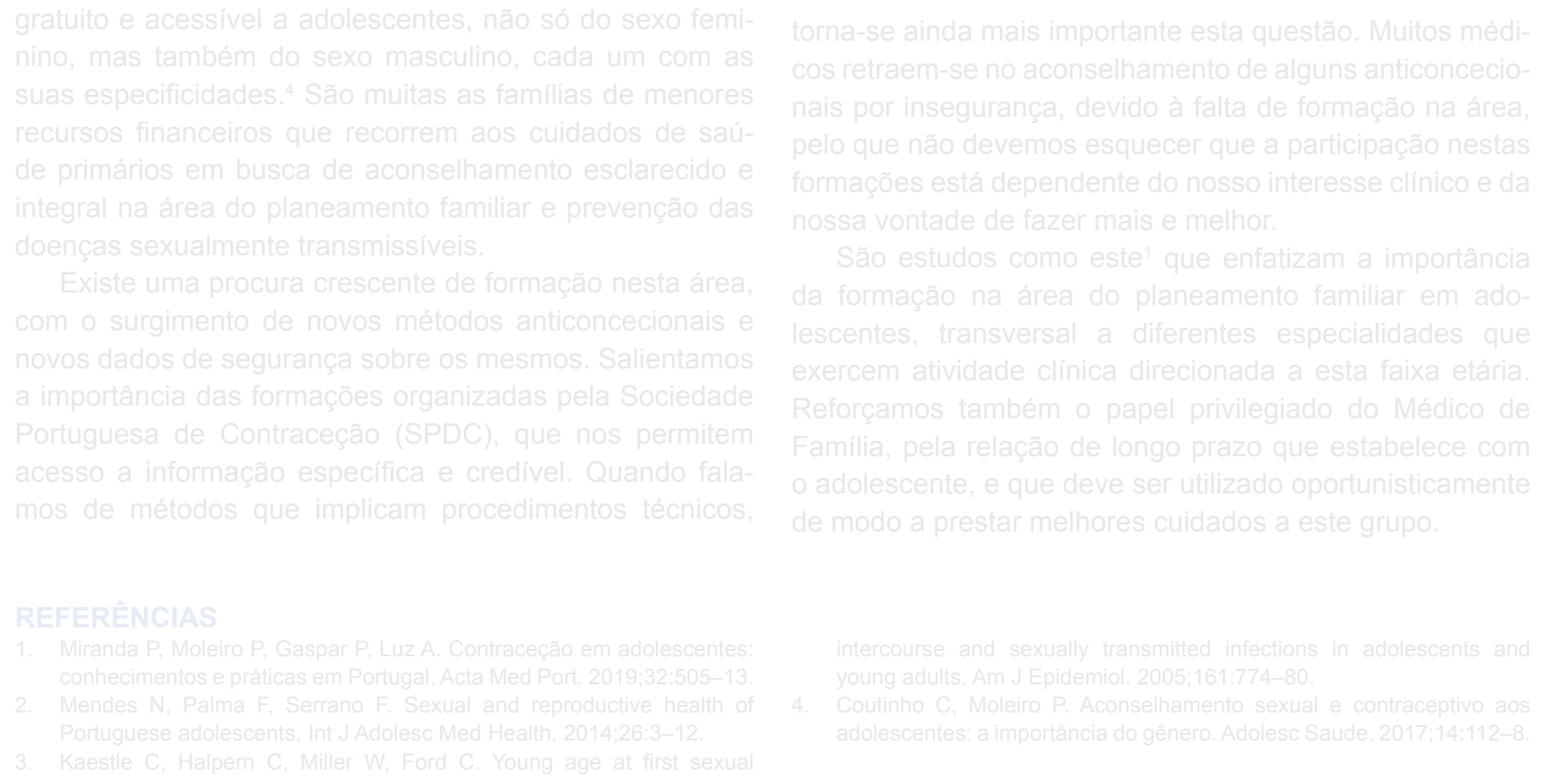

\section{Expor as Crianças Portuguesas ao Tabaco: Qual Será a Melhor Abordagem para Minimizá-lo?}

\section{Exposing Portuguese Children to Tobacco Smoke: What Could Be the Best Approach to Minimize It?}

Palavras-chave: Automóveis; Criança; Poluição do $\mathrm{Ar}$ em Ambientes Fechados; Poluição por Fumo de Tabaco; Portugal Keywords: Air Pollution, Indoor; Automobiles; Child; Portugal; Tobacco Smoke Pollution

\section{Caro Editor,}

Foi com interesse que li o artigo "Prevalência de Crianças Portuguesas Expostas ao Fumo Ambiental do Tabaco em Casa e no Carro"1 publicado no número de julho-agosto de 2019 da Acta Médica Portuguesa, que investiga a prevalência de crianças expostas ao fumo ambiental do tabaco em casa e no carro em Portugal. É de louvar a realização de estudos como este que nos informam dos dados atuais da população portuguesa, promovendo o planeamento das atitudes futuras relativamente a uma temática importante na saúde pública do país.

Apesar da extensa evidência científica acerca dos efeitos danosos da exposição ambiental ao tabaco nas crianças, é necessário priorizar uma educação para a saúde eficaz que consciencialize a população, almejando um impacto global na mesma, como tem vindo a ser concluído. ${ }^{2}$ Assim, seria importante divulgar os dados obtidos junto da população nas redes de comunicação comuns. A título de exemplo, a distinção entre a exposição ambiental secundária e terciária permite que a população compreenda que os malefícios do ato de fumar para os demais não se restringem aos efeitos naquele momento, dado que o fumo pode persistir nas superfícies durante semanas a meses. ${ }^{3}$

Apesar dos números não preocupantes, esta exposição é evitável e deve ser minimizada. A coordenação entre a Pediatria e a Medicina Geral e Familiar, no sentido do aconselhamento relativo à evicção de exposição ambiental nas crianças e à cessação tabágica, deveria ser uma prioridade na abordagem dos cuidados a ter para com a criança, orientando os pais para os recursos disponíveis na comunidade, tais como as consultas de Cessação Tabágica. ${ }^{4}$

O suporte informático SClínico ${ }^{\circledR}$ nos Cuidados de Saúde Primários contém, no separador específico para o Tabagismo, duas perguntas dirigidas à exposição ambiental e fumo passivo: "Está exposto ao fumo ambiental do tabaco?" e "Expõe outras pessoas ao fumo?" com os parâmetros "casa/trabalho/carro" para quantificar o número 
de horas por semana. Este instrumento permite responsabilizar os fumadores que fumam em espaços partilhados, mas também elucida os não fumadores que partiIham espaço com fumadores acerca deste risco para a sua saúde. Adicionalmente, permite ao médico adequar o tipo de abordagem mais conveniente. Para além disto, a

\section{REFERÊNCIAS}

1. Precioso J, Rocha V, Sousa I, Araújo AC, Machado JC, Antunes H. Exposure to secondhand smoke. Acta Med Port. 2019;32:499-504.

2. Jacob P, Benowitz NL, Destaillats H, Gundel LA, Hang B, MartinsGreen MM, et al. Thirdhand smoke: new evidence, challenges, and future directions. Chem Res Toxicol. 2017;30:270-94. crescente formação em Cessação Tabágica e consequente implementação de consultas dirigidas na Medicina Geral e Familiar melhora o acesso dos utentes ao apoio prestado, sendo uma vantagem com enorme potencial de impacto na vida dos utentes e crianças a si próximas.

\section{Marta BERNARDO $\square^{1}$}

1. Unidade de Saúde Familiar Andreas. Mafra. Portugal.

$\bowtie$ Autor correspondente: Marta Bernardo. wmartabernardo@gmail.com

Recebido: 15 de agosto de 2019 - Aceite: 19 de agosto de 2019 | Copyright (c) Ordem dos Médicos 2019 https://doi.org/10.20344/amp.12708

3. Duby JC, Langkamp DL. Another reason to avoid second-hand smoke. J Pediatr. 2015;167:224-5.

4. Roberts C, Wagler G, Carr MM. Environmental tobacco smoke: public perception of risks of exposing children to second- and third-hand tobacco smoke. J Pediatr Health Care. 2017;31:e7-13. 